\title{
Effects of Glucose on Rat Embryos in Culture
}

\author{
E. A. Garnham ${ }^{1}$, F. Beck ${ }^{2}$, C. A. Clarke, FRS ${ }^{3}$ and M. Stanisstreet ${ }^{1}$ \\ ${ }^{1}$ Department of Zoology, University of Liverpool, ${ }^{2}$ Department of Anatomy, The Medical School, University of Leicester and \\ ${ }^{3}$ Department of Genetics, University of Liverpool, Liverpool, UK
}

\begin{abstract}
Summary. To elucidate the role of hyperglycaemia in causing fetal malformation, rat embryos have been grown in vitro from the head-fold stage for $48 \mathrm{~h}$ in the presence of excess glucose during different parts of the culture period. Culture of rat embryos for 10 or $21 \mathrm{~h}$ in $55 \mathrm{mmol} / \mathrm{l}$ exogenous glucose produced abnormalities observable after $48 \mathrm{~h}$ in culture. When embryos cultured for 10 or $21 \mathrm{~h}$ in excess glucose were observed by scanning electron microscopy at the end of the glu-
\end{abstract}

cose treatment, abnormalities could be observed which may indicate how later malformations are formed. Thus it is possible that a relatively brief hyperglycaemic episode at a critical stage of embryogenesis may endanger the fetus of a diabetic mother.

Key words: Mammalian embryo culture, diabetes, glucose, hyperglycaemia.
Since Pederson et al. [1] observed that the incidence of congenital abnormalities in diabetic women was approximately three times that in a control group, considerable clinical evidence has accumulated which suggests that diabetic mothers are more likely to give birth to malformed infants than non-diabetic mothers. These malformations include defects of the heart and skeleton and abnormalities of the central nervous system such as anencephaly and spina bifida [2-3]. Abnormalities are also found in the offspring of laboratory rodents with natural diabetes [4], or with diabetes which has been induced by injection with alloxan or streptozotocin [5-7]. In addition, insulin replacement in alloxan- or streptozotocin-induced diabetic rodents prevents the increased incidence of abnormal embryos [8,9], and thus fetal abnormality appears to be due to some aspect of the diabetic state.

Drug-induced diabetes in rodents may provide a useful model for the study of diabetes-associated abnormal development in man. However, with in vivo experiments it is difficult to separate the teratogenic effects of the diabetic state from any direct effects of the diabetogenic agents and to distinguish which of the metabolic disturbances associated with diabetes are responsible for fetal malformation. The culture of rodent embryos in vitro allows the effects of individual teratogens to be assessed. For this reason in vitro culture of mammalian embryos has been employed to analyse the mechanisms of diabetes-associated abnormal development. Deuchar [10] cultured rat embryos in serum from normal and dia- betic rats from the late neurula stage for $24 \mathrm{~h}$ and found that diabetic serum had a beneficial effect on embryo growth compared with normal rat serum. However, Cockroft and Coppola [11] tested more directly the teratogenicity of glucose on rat embryos by culturing embryos from the head-fold stage in normal serum to which glucose had been added. Their results showed that $83 \mathrm{mmol} / \mathrm{l}$ glucose produced 'squirrel-like' abnormalities in which fusion of the neural folds was abnormal. Mouse embryos are apparently more susceptible to glucose, since embryos grown in serum which contained $22-33 \mathrm{mmol} / 1$ glucose showed abnormalities [12].

In the present study we have used the advantages of embryo culture in vitro to determine the effects of exposure to glucose for shorter periods within the $48 \mathrm{~h}$ culture. In addition, we have tried to gain information about the more immediate effects of glucose on the rat embryo by examining embryos which have been cultured in excess glucose at earlier developmental stages. So that the morphological abnormalities could be better assessed, embryos were examined by scanning electron microscopy.

\section{Materials and Methods}

\section{Rat Embryo Culture}

Embryos at the head-fold stage were obtained from random-bred Wistar rats at 9.5 days of gestation (timed from midnight preceding 

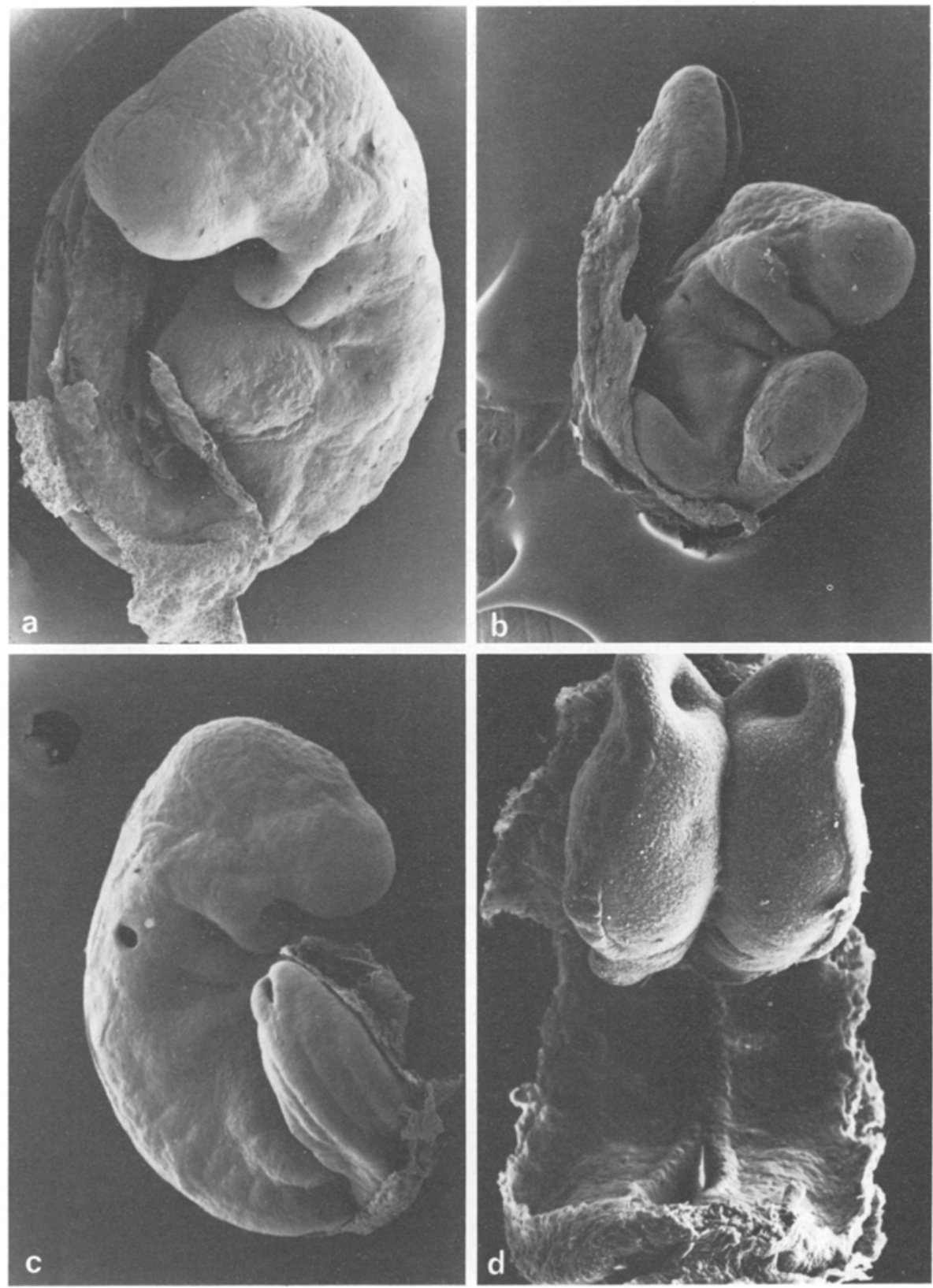

Fig. 1 a-d. Scanning electron micrographs of rat embryos explanted at 9.5 days and cultured in vitro. a Control embryo after $48 \mathrm{~h}$ culture is fully rotated and shows well developed brain vesicles $(\times 30)$. b After $48 \mathrm{~h}$ culture, the first $21 \mathrm{~h}$ being in $55 \mathrm{mmol} / 1 \mathrm{ex}$ ogenous glucose, the embryo has formed a 'squirrel-like' abnormality where the anterior and posterior regions of the neural tube have fused. In addition the posterior neuropore is open and the brain vesicles are not fully formed $(\times 34)$. c After $48 \mathrm{~h}$ culture, the last $27 \mathrm{~h}$ being in $55 \mathrm{mmol} / 1$ exogenous glucose, the embryo shows minor abnormalities and development is delayed; the optic pit and posterior neuropore are open and rotation is abnormal $(\times 33)$. d After $21 \mathrm{~h} \mathrm{cul}$ ture, the embryo is dorsally concave and the neural folds are raised and closed in the cervical region, and the cephalic region is well developed. The optic sulci have formed $(\times 109)$ the morning on which vaginal plugs were observed [13]). Embryos were explanted in Hank's balanced saline with sodium bicarbonate (Flow Laboratories, Irvine, UK) and cultured at $38^{\circ} \mathrm{C}$ in rotating glass bottles according to the method of New et al. [14]. Each bottle contained five embryos in $6 \mathrm{ml}$ of culture medium. The culture medium was pooled rat serum obtained from blood centrifuged immediately after withdrawal with added streptomycin $(100 \mu \mathrm{g} / \mathrm{ml})$ and penicillin (100 IU $/ \mathrm{ml}$, final concentrations) respectively. The serum was stored at $-20^{\circ} \mathrm{C}$ and heat-inactivated at $56^{\circ} \mathrm{C}$ for $30 \mathrm{~min}$ immediately before use. Glucose $(300 \mathrm{mmol} / 1,1.1 \mathrm{ml}$, corrected to serum osmolarity of $300 \mathrm{mOsm}$ ) was added to $5 \mathrm{ml}$ serum to give a final concentration of $55 \mathrm{mmol} / \mathrm{l}$ exogenous glucose. Control cultures received $1.1 \mathrm{ml}$ Hank's saline.

Initially the culture bottles were equilibrated with $\mathrm{O}_{2} / \mathrm{CO}_{2} / \mathrm{N}_{2}$ $(5: 5: 90)$. After 24 and $45 \mathrm{~h}$ the cultures were re-equilibrated with gas ratios $(20: 5: 75)$ and $(40: 5: 55)$ respectively [15].

In the first set of experiments embryos were cultured for $48 \mathrm{~h}$ but exposed to excess glucose from 0 to $21 \mathrm{~h}$ or 21 to $48 \mathrm{~h}$. At the end of the 48-h culture period, the yolk-sac diameter and crown-rump lengths of embryos were estimated, and the embryos scored for heart beat, yolk-sac circulation and somite number, and any abnormalities were noted. The embryos were then fixed for scanning electron microscopy. As a sub-set of this experiment, embryos were incubated in excess glucose from 0 to $21 \mathrm{~h}$ and then examined by scanning electron microscopy. In the second set of experiments, embryos were cultured for $48 \mathrm{~h}$ but exposed to excess glucose from 0 to $10 \mathrm{~h}$ or 10 to $48 \mathrm{~h}$. At the end of the 48-h culture period embryos were scored as above and fixed for scanning electron microscopy. As a sub-set of this experiment, embryos were incubated in excess glucose for 0 to $10 \mathrm{~h}$ and then examined by scanning electron microscopy.

\section{Scanning Electron Microscopy}

Embryos were fixed overnight in $2 \%$ glutaraldehyde in $0.1 \mathrm{~mol} / 1 \mathrm{ca}-$ codylate buffer, $\mathrm{pH} 7.3$ [16]; they were washed in changes of $0.1 \mathrm{~mol} / 1$ cacodylate buffer ( $\mathrm{pH} 7.3$ ) and dehydrated in a graded acetone series. The absolute acetone was replaced with liquid $\mathrm{CO}_{2}$, and the embryos 

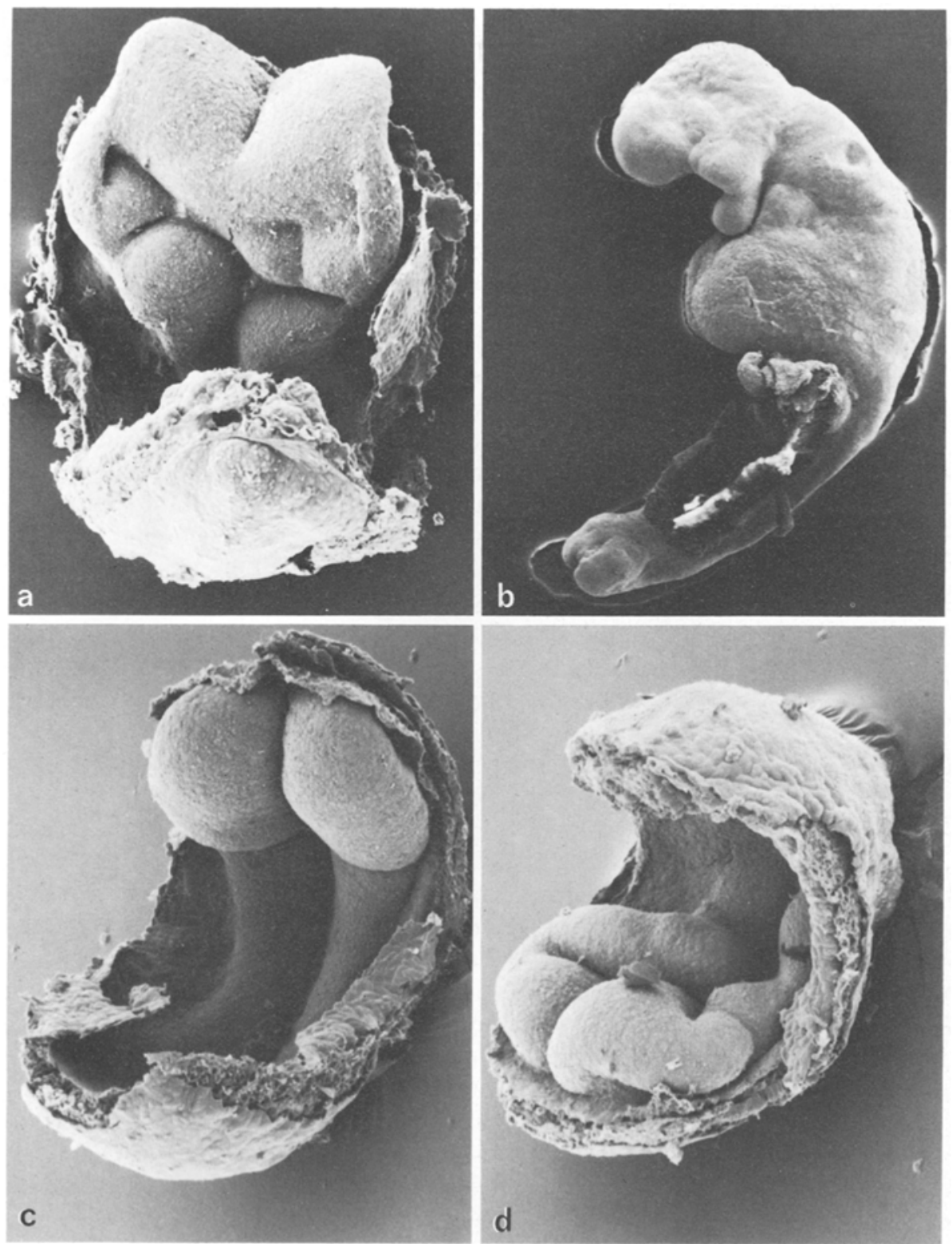

Figure 2a-d. Scanning electron micrograph of rat embryos explanted at 9.5 days and cultured in vitro in exogenous glucose $(55 \mathrm{mmol} / \mathrm{l})$. a After $21 \mathrm{~h}$ culture the embryo is more dorsally concave than control embryos so that the tail and cephalic region are more closely apposed. The neural folds are poorly developed in the cephalic region and are abnormally grooved $(\times 121)$. b After $48 \mathrm{~h}$ culture, the last $38 \mathrm{~h}$ being in $55 \mathrm{mmol} / \mathrm{l}$ exogenous glucose, the embryo has failed to rotate and is delayed in development; the optic pit and posterior neuropore are open and the brain vesicles are retarded $(\times 44)$. c After $10 \mathrm{~h}$ culture, the embryo is dorsally concave and the neural folds are beginning to rise $(\times 118)$. d After $10 \mathrm{~h}$ culture, the embryo is dorsally concave and the neural folds show abnormal grooves $(\times 133)$ were dried using the critical point method. The dried specimens were mounted on stubs. Finally the embryos were coated with a gold-palladium mixture and observed and photographed using a Phillips 501B scanning electron microscope (Pye Unicam, Cambridge, UK).

\section{Results}

By the end of the 48-h culture period control embryos had reached the 21-23 somite stage. The neural folds had fused and the major brain vesicles formed (Fig. 1 a). The heart was beating and a yolk-sac circulation had been established. Preliminary experiments in which embryos were exposed to $55 \mathrm{mmol} / 1$ excess glucose throughout the culture period confirmed that the major abnormality following this treatment was a 'squirrellike' embryo in which the cephalic region of the neural folds was fused with the caudal region of the neural folds, rather than with the contralateral cephalic fold [11]. A number of other abnormalities were observed including microcephaly, failure of rotation, irregular somites and crooked neural tube.

In the first set of experiments embryos were cultured in $55 \mathrm{mmol} / 1$ excess glucose from 0 to $21 \mathrm{~h}$, or 21 to $48 \mathrm{~h}$ and scored after $48 \mathrm{~h}$ of culture. The results show that rat embryos are more susceptible to excess glucose during the first $21 \mathrm{~h}$ of culture, from the head-fold stage to the 7-8 somite stage, than during the last $27 \mathrm{~h}$ of culture, from the 7-8 somite stage to the 23 somite stage (Table 1). Some of the embryos had formed the 'squirrel-like' abnormality (Fig.1b); some embryos showed more minor abnormalities (Fig. 1c). Comparison of yolk-sac diameters showed no significant difference between the control and treated groups, and so glucose 
Table 1. Effect on rat embryos of exposure to excess glucose $(55 \mathrm{mmol} / 1)$ for first $21 \mathrm{~h}$ or last $27 \mathrm{~h}$ of $48 \mathrm{~h}$ culture in vitro

\begin{tabular}{|c|c|c|c|c|c|}
\hline \multirow[t]{2}{*}{ Rat embryos } & \multicolumn{2}{|c|}{ Abnormalities } & \multirow[t]{2}{*}{ Somite no. } & \multirow{2}{*}{$\begin{array}{l}\text { Yolk sac } \\
\text { diameter } \\
(\mathrm{mm})\end{array}$} & \multirow{2}{*}{$\begin{array}{l}\text { Crown- } \\
\text { rump length } \\
\text { (mm) }\end{array}$} \\
\hline & 'Squirrel' & Other & & & \\
\hline Control $(n=30)$ & 1 & 3 & $23.8 \pm 0.6$ & $3.47 \pm 0.11$ & $2.85 \pm 0.07$ \\
\hline $\begin{array}{l}\text { Glucose } \\
0-21 \mathrm{~h} \text { culture } \\
(n=33)\end{array}$ & 14 & 5 & $24.7 \pm 0.3$ & $3.19 \pm 0.10$ & $2.85 \pm 0.11$ \\
\hline $\begin{array}{l}\text { Glucose } \\
21-48 \text { h culture } \\
(n=28)\end{array}$ & 3 & 7 & $23.8 \pm 0.8$ & $3.19 \pm 0.21$ & $2.82 \pm 0.08$ \\
\hline
\end{tabular}

Results expressed as mean \pm SEM

Table 2. Effect on rat embryos of exposure to excess glucose $(55 \mathrm{mmol} / \mathrm{l})$ for first $10 \mathrm{~h}$ or last $38 \mathrm{~h}$ of $48 \mathrm{~h}$ culture in vitro

\begin{tabular}{|c|c|c|c|c|c|}
\hline \multirow[t]{2}{*}{ Rat embryos } & \multicolumn{2}{|c|}{ Abnormalities } & \multirow[t]{2}{*}{ Somite no. } & \multirow{2}{*}{$\begin{array}{l}\text { Yolk sac } \\
\text { diameter } \\
(\mathrm{mm})\end{array}$} & \multirow{2}{*}{$\begin{array}{l}\text { Crown- } \\
\text { rump length } \\
\text { (mm) }\end{array}$} \\
\hline & 'Squirrel' & Other & & & \\
\hline Control $(n=27)$ & 1 & 4 & $20.6 \pm 0.3$ & $3.46 \pm 0.07$ & $2.81 \pm 0.07$ \\
\hline $\begin{array}{l}\text { Glucose } \\
0-10 \mathrm{~h} \text { culture } \\
(n=25)\end{array}$ & 3 & 1 & $20.9 \pm 0.3$ & $3.38 \pm 0.07$ & $2.81 \pm 0.06$ \\
\hline $\begin{array}{l}\text { Glucose } \\
10-38 \text { h culture } \\
(n=26)\end{array}$ & 4 & 10 & $20.7 \pm 0.3$ & $3.22 \pm 0.08$ & $2.80 \pm 0.08$ \\
\hline
\end{tabular}

Results expressed as mean \pm SEM

appeared not to have a major effect on yolk-sac expansion. Because of the abnormal morphology of some embryos in the treated group, not all were scored for somite number; because of abnormal rotation some embryos were not scored for crown-rump length. Those that were scored showed no significant difference from the control group.

As a sub-set to this experiment embryos were exposed to $55 \mathrm{mmol} / 1$ excess glucose from the head-fold stage for $21 \mathrm{~h}$ and then scored and examined by scanning electron microscopy. Embryos cultured in normal serum for $21 \mathrm{~h}$ served as controls. Light microscopical observations showed that control embryos after $21 \mathrm{~h}$ were at the 7-8 somite stage. The embryos had not yet undergone rotation, and were still dorsally concave. Scanning electron microscopy of control embryos showed that the neural tube had closed in the mid-region, and that the cephalic folds were apposing each other. The optic sulci had formed (Fig. 1d). Higher power observations of the neural tube revealed that the cells in the neural folds appeared rounded, whereas those on the outside of the neural folds were more flattened. This observation suggests that cells within the neural folds were under lateral compression as the folds closed and that cells on the outside of the neural folds were stretched. Scanning electron microscopy showed that of the 27 glucose-treated embryos 12 were abnormal, and revealed a variety of abnormalities. Some embryos were more dorsally concave than controls with the caudal region closely apposed to the cephalic region. In all ad- versely affected embryos the neural folds were abnormally grooved and the fusion of the folds appeared delayed since the cephalic folds were flatter than those of normal embryos, which were raised (Fig. 2 a). Such abnormalities might represent the precursor of the characteristic 'squirrel-like' embryo seen after $48 \mathrm{~h}$ culture.

In the second set of experiments embryos were cultured in $55 \mathrm{mmol} / 1$ excess glucose from 0 to $10 \mathrm{~h}$ or 10 to $48 \mathrm{~h}$ and scored after $48 \mathrm{~h}$ in culture. The results suggest that the embryos are more susceptible to excess glucose during the last $38 \mathrm{~h}$ of culture, between the 3-4 somite stage and the 21 somite stage, than during the first $10 \mathrm{~h}$ of culture, from the head-fold stage to the 2-3 somite stage, judged by the occurrence of general abnormalities (Table 2). Some embryos had formed the 'squirrel-like' abnormality, whereas other embryos showed different abnormalities such as failure to rotate and open neuropore (Fig. 2b). The incidence of 'squirrel-like' abnormal embryos was similar in both treated groups, although the total proportion of 'squirrel-like' embryos was less than the total proportion of such embryos under conditions of exposure for the first $21 \mathrm{~h}$. Comparison of yolk-sac diameters showed no significant difference between embryos treated with glucose for the first $10 \mathrm{~h}$ of culture and controls, but embryos treated with glucose for the last $38 \mathrm{~h}$ of the culture showed less yolk sac expansion than controls $(p<0.05)$. Somite number and crown-rump lengths of the scorable embryos were not different between control and treated groups.

As a sub-set of this experiment embryos were exposed to $55 \mathrm{mmol} / 1$ excess glucose for $10 \mathrm{~h}$ from the head-fold stage and then scored and examined by scanning electron microscopy. Embryos cultured in normal serum for $10 \mathrm{~h}$ served as controls. The control embryos had 2-4 somites and were at the neural groove stage, with the cephalic folds becoming prominent (Fig. 2c). Scanning electron microscopy showed that of the 22 embryos exposed to excess glucose, 18 were abnormal. A common abnormality was that the neural folds were assymetric, the neural groove being crooked (Fig. 2d).

\section{Discussion}

Glucose is teratogenic to both mouse [17] and rat [11] embryos. The present results confirm this observation for rat embryos, and demonstrate that the embryos may develop abnormally when exposed to glucose for relatively brief periods. In addition, scanning electron microscopy showed that abnormalities of the neural tissue are present after only $10 \mathrm{~h}$ exposure to glucose. Exposure to elevated levels of glucose may be one of the factors responsible for fetal abnormalities associated with maternal diabetes in women. The susceptibility of human early embryos to raised levels of glucose is not known but diabetic women might achieve teratogenic 
levels of blood glucose during peaks of hyperglycaemia which may occur without symptoms in early pregnancy. In addition, a change in the level of blood glucose at a critical stage of embryonic development might be more deleterious to the embryo than a constant elevated level [18]. Thus it is possible that a relatively short, undetected episode of hyperglycaemia resulting from diabetes or even a disturbed glucose balance during non-diabetic pregnancy at a critical stage of embryogenesis might be sufficient to produce fetal malformation.

One of the major types of abnormality was a defect in the neural tube. Successful neurulation involves a morphogenetic event, the raising and subsequent apposition of the neural folds, followed by a cellular adhesive event, the fusion of neural folds to produce the neural tube. Observations of embryos after $21 \mathrm{~h}$ in culture suggest that the elevation of the neural folds was delayed and that the embryos had flexed abnormally such that the caudal and cephalic regions were apposed. The 'squirrel-like' abnormality characteristic of rat embryos exposed to excess glucose might be a result of the fusion of the anterior and posterior regions of either fold. In addition, spina bifida abnormalities could be a result of a failure of the apposition of the neural folds rather than a failure of their fusion; what appears to be a failure of cell adhesion might be due to a failure or delay of a preceding morphogenetic movement. However, any explanation of the cellular mechanisms of neural tube abnormalities must encompass the observation that other agents can cause neural defects; sodium salicylate can cause 'squirrel-like' abnormalities in rat embryos [19], and open posterior neuropore can be caused by exposure of embryos to homogenates of placental and decidual tissues [20], or by raised oxygen tension [21]. In addition, hyperglycaemia may not be the only teratogenic component of diabetes. There are other potentially teratogenic disturbances, such as hypoinsulinaemia, ketosis and lactic acidosis, and it is possible that the increased occurrence of fetal abnormality associated with maternal diabetes is due not to hyperglycaemia alone, but to the synergistic action of such factors with hyperglycaemia.

Acknowledgements. We wish to thank Mr. K. Veltkamp and Mr. B. Lewis for their expert assistance with the scanning electron microscopy and photography, Miss A.Callaghan and Miss S. Scott who typed the manuscript and an anonymous donor for finanacial support for EAG

\section{References}

1. Pederson LM, Tygstrup I, Pederson J (1964) Congenital malformations in newborn infants of diabetic women: correlations with maternal diabetic vascular complications. Lancet 1:1124-26
2. Soler NG, Walsh CH, Malins JM (1976) Congenital malformations in infants of diabetic mothers. Quart J Med 45: 303-313

3. Gabbe SG (1977) Congenital malformations in infants of diabetic mothers. Obstet Gynecol Surv 32: 125-132

4. Angervall L (1959) Alloxan diabetes and pregnancy in the rat. Effects on offspring. Acta Endocrinol (Suppl) 44: 1-86

5. Watenabe G, Ingalls TH (1973) Congenital malformations in the offspring of alloxan diabetic mice. Diabetes 12: 66-72

6. Deuchar EM (1977) Embryonic malformations in rats, resulting from maternal diabetes: preliminary observations. J Embryol exp Morph 41: 93-99

7. Rerup CC (1970) Drugs producing diabetes through damage of the insulin secreting cells. Pharmacol Rev 22: 485-520

8. Horrii K, Watenabe G, Ingals TH (1966) Experimental diabetes in pregant mice: prevention of congenital malformations in of spring by insulin. Diabetes 15: 194-204

9. Baker L, Egler JM, Klein SM, Goldman AS (1981) Meticulous control of diabetes during organogenesis prevents congenital lumbrosacral defects in rats. Diabetes 30: 955-959

10. Deuchar EM (1979) Culture in vitro as a means of analysing the effect of maternal diabetes on embryonic development in rats. In: Elliot K, O'Connor M (eds) Pregnancy, metabolism, diabetes and the fetus. Ciba Foundation Series 63, pp 181-197

11. Cockroft DL, Coppola PT (1977) Teratogenic effects of excess glucose on head-fold rat embryos in culture. Teratology 16: 141-146

12. Sadler TW (1980) Effects of maternal diabetes on early embryogenesis: I. The teratogenic potential of diabetic serum. Teratology 21: 339-347

13. New DAT (1978) Whole embryo culture and the study of mammalian embryos during organogenesis. Biol Rev 53: 81-122

14. New DAT, Coppola PT, Terry S (1973) Culture of explanted rat embryos in rotating tubes. J Reprod Fertil 35: 135-138

15. New DAT, Coppola PT, Cockroft DL (1976) Improved development of head-fold rat embryos in culture resulting from low oxygen and modifications of the culture serum. J Reprod Fertil 48: 219-222

16. Karnovsky MY (1965) A formaldehyde/glutaraldehyde fixative of high osmolarity for use in electron microscopy. J Cell Biol 27 : 137A-138A

17. Sadler TW (1980) Effects of maternal diabetes on early embryogenesis: II. Hyperglycemia-induced exencephaly. Teratology 21: 349-356

18. Reid RA (1970) Diabetes and congenital abnormalities. Lancet 1: 1030-1031

19. McGarrity C, Samani N, Beck F, Gulamhusein A (1981) The effect of sodium salicylate on the rat embryo in culture: an in vitro model for the morphological aspect of teratogenicity. J Anat 133: 257-269

20. Huxam IM, Gupta M, Azoubel R, Beck F (1982) Dose dependent induction of abnormalities by tissue homogenates of placenta and decidua. Br J Exp Pathol 63: 95-102

21. Morriss GM, New DAT (1979) Effect of oxygen concentration on morphogenesis of cranial neural folds and neural crest in cultured rat embryos. J Embryol Exp Morphol 54: 17-35

Received: 27 October 1982

and in final form: 27 April 1983

Dr. M. Stanisstreet

Department of Zoology

University of Liverpool

P.O. Box 147

Liverpool L69 3BX, UK 